\title{
The FDI psychic distance paradox: Myth or reality?
}

\author{
David Alastair Lindsay Coldwell \\ Tasneem Joosub
}

University of the Witwatersrand, South Africa

\section{Keywords}

Psychic distance, psychic distance paradox, foreign direct investment

\begin{abstract}
Psychic distance is derived from the Greek word psychikos which refers to an individual's mind and distance refers to degree of psychological gap when specific individuals consider subjective and objective phenomena. It is regarded as an individual's subjective perception of phenomena and their unique subjective distance of these phenomena from their own psychikos or 'mind's eye.' In the business context, Psychic Distance refers to the tendency of companies embarking on internationalization to choose countries that are psychically close in terms of a number of key criteria that make business success easier to achieve, including: language, geographical proximity and historical and cultural ties. In this regard, the 'Psychic Distance Paradox' concept originally arose from an attempt to explain contradictory evidence from Canadian companies that had embarked on FDI in the physically close USA, which indicated that only a few had been functionally successful.

The current paper purpose is to investigate whether psychic distance and the psychic distance paradox provide cogent theoretical and empirical models; or whether they arise from a methodological approach built on a unidirectional, 'deficit model' consisting of lists of objectives (researcher conceived) 'psychic factors' obtained from the internationalization experiences of countries.

The paper critically analyses the concepts of psychic distance and its paradox as theoretically and logically cogent constructs based on valid and rigorous empirical evidence. It aims to contribute to the extant literature by providing an original theoretical critique and describing an example of a recent South African empirical study that potentially surpasses the original psychic distance methodological approach by considering quantitative and qualitative context-specific factors in a triangulated quantitative and qualitative cross-sectional research design.

Findings of the theoretical and empirical analyses suggest that Psychic Distance and the Psychic Distance Paradox may be more myth than reality, and may derive from the limitations of the model's deficitfocused configuration its emphasis on objective measurement indices and a paucity of qualitative data.
\end{abstract}

Corresponding author: David Alastair Lindsay Coldwell

Email addresses for corresponding author: David.coldwell@wits.ac.za

First submission received: 26th May 2017

Revised submission received: 27th June 2017

Accepted: 20th July 2017

\section{Introduction}

In the business context, Psychic Distance has been defined as the advantage of internationalizing companies that choose countries that are 'psychically close' in terms of a number of key criteria that make business success easier to achieve, including: language, geographical proximity and historical and cultural ties. The 'Psychic Distance Paradox' concept original definition arose from an attempt to explain contradictory evidence obtained from Canadian companies that had embarked on Foreign Direct Investment (FDI) in the 'psychically close' USA, which indicated that only a few had been functionally successful. In other words, the paradox was defined in terms of the empirically established fact that low psychic distance was not necessarily associated with company success in foreign localities. In fact, the term 'Psychic Distance' has a long history with, unsurprisingly, a specifically psychological origin Bullough (1912) in an article in the British Journal of Psychology referred to it in relation to aesthetics and in the sense, he used it, meant distancing oneself from our appeal of an object (work of art) by putting our perception 'out of gear' with practicalities and making the focus of our contemplation of the object complete. This original use of the term 'Psychic Distance' is clearly far removed from its use in 
International Business in which it emerges in various forms distinct from its original meaning in the field.

The Uppsala internationalisation school originally defined Psychic Distance as 'the sum of factors preventing or disturbing the flows of information between firms and markets' (Johanson \& WiedersheimPaul 1975:308). However, there have been many further definitions and implementations of the concept in International Business. Stemming from the original definition of information flow disturbances has been the more recent interpretation and meaning attached to the concept that of distance where further distance is equated with greater information disturbances which, as Brewer (2007) points, out may or not be the case and where distance is seen largely in terms of geographical and cultural proximity. Thus, Vahlne and Wiedersheim-Paul (1973) defined psychic distance as "factors preventing or disturbing [a] firm's learning about and understanding [of] a foreign environment" (Nordstrom \& Vahlne, 1994:42). As Brewer (2007:.74) points out: "The connection between psychic distance and knowledge is that a firm's managers will tend towards those country markets that they can get to know most easily, and they will avoid those it is difficult to get to know. It is further postulated that psychic distance is a result of perceived business differences between the firm's home environment and that of foreign country market(s)". In effect the original very broadly defined deficit model of Psychic Distance as distortions in information flows has been narrowed down to ease or difficulty in understanding a foreign environment to, most recently, specific objectively measurable aspects that make understanding the foreign environment difficult. For example, Stottinger and Schlegelmilch's (2000) cultural proximity; Evans, Treadgold and Mavondo's (2000a) cultural and business differences; Conway and Swift's (2000) separate national identities; Child, $\mathrm{Ng}$ and Wong's (2002) differences in languages, culture, political systems, level of education and level of development; Chetty and Campbell-Hunt's (2004) differences from the home country in terms of language, culture, political system, business practice, industrial development and education systems, and Dow and Karunaratna's (2006) differences in culture, languages, religions, education and political systems.

O'Grady and Lane (1996) used the 'Psychic Distance Paradox' concept to describe evidence from 32 Canadian retail companies which had embarked on FDI in the physically close USA but of which only 7 companies $(22 \%)$ had been functionally successful there. The researchers suggest that this finding suggests a 'Psychic Distance Paradox' since it had been found that psychically close countries were not always easy to manage and were not as successful as had been assumed. This was because assumed international similarities often hide subtle, but critical, cultural and operational differences which tend to remain unrecognized and accounted for.

However, definitions implementations and derivations of the original information flow deficit model of psychic distance are eclectic in the variables selected for the measurement of Psychic Distance, and lack the necessary broadness and scope and openness to subjectively interpreted inputs of meaning to validly reflect the real-world process of internationalization decision-making.

The essential point being raised in the foregoing discussion is that there cannot be a psychic distance paradox if the definitions and usage of the concept of Psychic Distance itself are arbitrary and eclectic and narrow in scope and do not adequately consider the pivotal role of the perceiver and his/her subjective interpretations of what constitutes their predilections and priorities in their foreign investment decision-making.

The paper takes the following form. The next section presents a brief literature review with a focus on Brewer's (2007) work in trying to give a comprehensive objectively measurable index of what Psychic Distance consists of. This is followed by a section that deals with literature concerning the Psychic Distance Paradox and describes recent findings using computerized simulations of Psychic Distance and Psychic Distance Paradox (Gairola and Chong, 2012) and criticisms of the concepts that can be derived from this study and other recent empirical data. There then follows a description of a methodological approach used in a recent empirical study conducted in South Africa that focuses on FDI (Foreign Direct Investment) decision making among SA executives. The study suggests that a broader, nomothetic and ideographically-oriented approach to Psychic Distance is more valid than the extant nomothetic 'deficit' model of Psychic Distance, and renders the extant concept of Psychic Distance Paradox obsolescent. This is followed by the conclusion that concludes from the foregoing arguments regarding the psychic paradox, outlines limitations of the study and presents recommendations for further research. 


\section{Literature review}

Psychic distance

The business origins of the "psychic distance" have their roots in research performed by Beckerman (1956) and Linnemann (1966), but Vahlne and Wiedersheim-Paul (1973) as cited by Nordstrom and Vahine (1994) as indicated above were the first to conceptualize psychic distance as disturbances or preventions in flow of information between potential and actual suppliers and customers. These flow disturbances are associated with country-based differences and are grouped into four major clusters of factors that impede information flows namely: linguistic differences, cultural factors, economic factors and, political and legal system factors.

Johanson and Vahlne's (1977) study of Nordic multinationals surmised that a firm's international activities which include FDI relate to psychic distance and that international expansion progresses from markets with lower psychic distance to markets with successively higher psychic distance. Companies tend to export to countries that have the least information deficits and then progressively advance into markets further afield. The original psychic distance model suggests that firms enter new markets with opportunities with few market uncertainties and later enter markets at with progressively greater information flow disturbances. The process of internationalization considers psychic distance as a key factor in the explanation of the expansion of firms into foreign markets.

Johanson and Wiedersheim-Paul (1975) were the first authors to make the conceptual link between psychic distance and the internationalisation process. The Uppsala model proposed the role of psychic distance in the internationalisation behaviour of a firm and postulated that the more distant the market, the more difficult it is for new firms to fit into the foreign business environment. The higher the psychic distance the greater the risk of the internationalisation venture on (Arenius, 2005). Zaheer (1995) lists four sources of foreign investment risk:

- General costs, including costs of travel, transportation and management co-ordination over large distances and across time zones;

- Firm-specific costs based on information costs incurred through the unfamiliarity of the foreign environment;

- Costs arising from the host country's specific environment, such as tax and registration surcharges and from economic nationalism;

- Costs present in the home country environment, such as nationalisation, and government restrictions on foreign investment.

The psychic distance concept has been used as a key conceptual factor in explaining expansion strategies of firms (Stöttinger and Schlegelmilch, 2000; Bai and Sarkis, 2010; Covin and Miller, 2014). Pioneering research in the area supports the view that companies perform best in foreign markets that resemble their domestic markets closely. The 'common sense' relationship between psychic distance and organisational performance is seen as the generally plausible premise that psychically close countries are easier to understand (Cavusgil, 1980: Nordström and Vahlne, 1994; Evans, Treadgold and Mavondo, 2000; Campbell, Eden and Miller, 2012) and that the level of uncertainty faced by companies investing in foreign countries closer to home is likely to be reduced.

For example, Asian firms appear to support the psychic distance concept in their internationalisation process. This is evident in the growth of the Asian MNE's in the 1980s and 1990s, through their inter-regional direct investments (Sim and Pandian, 2003; Dent, 2016; Kotabe, Jiang and Murray, 2011). FDI is transferred from one level of Asia's economy to another, from Japan, to the NICs (Korea, Taiwan, Hong Kong and Singapore), and then to the rapidly growing economies such as Indonesia, Malaysia and Thailand, a process of industrialization sometimes referred to as the "wild flying geese pattern".

Similarly, Amighini, Rabellotti and Sanfilippo (2013), found that the international guanxi system of social networks and relationships among Chinese diaspora seems to be a significant factor in location decisions. The use of network alliances reduces psychic distance in different countries and networks of overseas Chinese nationals are considered a crucial source of trustworthy information for Chinese companies in more psychically distant markets and can affect the success or failure of the investment made. Blomkvist and Drogendijk (2013) also found that Chinese FDI is affected by an 'aggregated' 
construct of psychic distance which includes measures of, inter alia: similarities in language and culture, levels of industrialisation and the strength of local democratic institutions.

Other researchers indicate that companies perform better in foreign markets which are psychically close because they are more readily understood and business information, building knowledge and forming networks easier to acquire and assimilate (e.g. Evans et al., 2000; Campbell et al., 2012) and that this reduces risks associated with investing in a foreign country and in setting up operations ( Cavusgil, 1980; Johanson and Vahlne, 1977; Nordström and Vahlne, 1994; Lee 1998; Evans et al., 2000; Rugman, Verbeke and Nguyen, 2011; Kiss, Danis and Cavusgil, 2012).

Recent findings byHolm, Forsgrenand Johanson. (2015), and Ekroos and Sjöberg (2012) also confirm that companies perform better in psychically close countries.

Conversely, Li and Guisinger (1992) found that US affiliates business failure was significantly higher when the parent company was based in a culturally distant country compared with those culturally close. These authors have all purported shown that psychic distance, loosely defined, provides a 'conceptual umbrella' to explain variations in the performance of parent companies in foreign locations. But the empirical evidence in this regard is by no means unanimous. For example, Benito and Gripsrud (1992), found in a study of Norwegian companies, did not find support for the notion that FDI undertaken by Norwegian MNEs occurs in culturally close countries. They found that the selection of location by Norwegian MNEs seemed to be based on much broader rational economic considerations than simply psychic proximity. Similarly, O'Grady and Lane (1996) found that specific Canadian retail companies were not successful in the psychically close United States business environment. Thus, empirical data suggests that support for psychic distance as an explanatory concept is not unanimous, even in its most broadly defined implementations. The concept of psychic distance as an independent variable in the explanation of successful FDI is thus brought into question on empirical and conceptual grounds.

The conceptual weakness and measurement difficult of psychic distance has recently been identified Brewer (2007) and measures and prescriptive remedial steps taken to resolve the problem through the construction of a 'psychic distance index'. In this regard Brewer (2007) maintains that the operationalization of key factors of the concept of 'psychic distance' in its current, broadly defined form can be achieved by constructing an umbrella psychic distance index. The psychic distance index comprises aspects of psychic distance derived from the extant literature and combined as an aggregated construct and operationalized in a specially designed measuring instrument. The elements of the psychic distance index construct devised by Brewer (2007) were obtained from factors used by Australian exporters in their FDI decision-making processes. The psychic distance index included factors which were based on "subjective judgment plus data availability" (Lockwood, 2004: 507).

Brewer's (2007) measuring instrument aims at eliciting data from individual FDI decisionmakers. The measures Brewer (2007) suggests as indexes of psychic distance are indicated in Table 1.

\begin{tabular}{|c|c|}
\hline Measure & Description of measure \\
\hline Commercial ties & $\begin{array}{l}\text { Existing commercial relationships between countries based on } \\
\text { exchange of goods and services. Existing commercial exchanges } \\
\text { are adding to overall knowledge about a country and businesses } \\
\text { operating in these countries. }\end{array}$ \\
\hline Political ties & $\begin{array}{l}\text { Political ties can enhance relationships of businesses in foreign } \\
\text { countries and reduce information distortions. }\end{array}$ \\
\hline $\begin{array}{lr}\text { Information } & \text { availability- } \\
\text { Trade } & \text { agreements, } \\
\text { defense } & \text { treaties, } \\
\text { diplomatic } & \text { connections } \\
\text { and aid programs. } & \end{array}$ & $\begin{array}{l}\text { Information availability generates enhanced awareness between } \\
\text { countries. }\end{array}$ \\
\hline Historical ties & $\begin{array}{l}\text { Countries that share historical ties (e.g. a colonial relationship), } \\
\text { tend to be closer in terms of institutions, mutual familiarity and } \\
\text { understanding. }\end{array}$ \\
\hline Geographical proximity & $\begin{array}{l}\begin{array}{l}\text { Geographical distances between countries affects ease of } \\
\text { commercial exchanges }\end{array} \\
\end{array}$ \\
\hline Country's level & Highly developed countries generally have better information \\
\hline
\end{tabular}




\begin{tabular}{|l|l|}
\hline development & $\begin{array}{l}\text { availability, a more amenable business environment and less } \\
\text { corruption }\end{array}$ \\
\hline Social ties & $\begin{array}{l}\text { Differences culture and language used affect the information and } \\
\text { knowledge inflows. }\end{array}$ \\
\hline
\end{tabular}

Table 1 - Brewer's (2007) psychic distance index

Brewer (2007) used the specially constructed psychic distance index to measure exporting frequency between Australia and twenty-five other countries and found that the concept of psychic distance provided a significant level of predictive validity. Brewer's (2007) index used numbers 1 and 0 to indicate the extreme measurement values of the index pertaining to a specific independent variable where $1=$ the most psychic distance and $0=$ the least psychic distance. Intermediate numbers are given to relative values between 0 and 1 (Lockwood 2004). "Summation of the individual psychic distance elements for each country leads to an index number on an interval scale. The closest index value that a country can have with respect to another country is 0 , and the farthest is 15 (the total number of index indicators" (Brewer 2007:56). Brewer (2007) found that countries having the closest psychic distance (lower psychic distance index score) tended to have the largest number of Australian exporters selling in their markets. Thus, the UK and the US with psychic distance index scores of 4.80 and 5.27 respectively, were ranked first and second on psychic distance. In contrast, Kenya which was ranked bottom on psychic distance, obtained a psychic distance index score of 11.51 .

Brewer (2007:87), however, recognizes that: "Information exchange is at the heart of the original Johanson and Wiedersheim-Paul (1975) psychic distance definition based on ease of information flows. But there has been an important departure from this original definition in the most common forms of psychic distance interpretation in the literature, namely, country differences. The extrapolation of psychic distance from 'factors impeding the flow of information' to 'country differences' is unsupported by other than recognition that such differences should affect business relationships. The direct definitional relationship between psychic distance and ease of information flows has been corrupted to a direct one-toone relationship between psychic distance and differences between countries". Brewer (2007) suggests that the development of the psychic distance index goes some way in resolving this by offering a number of variables for measurement of psychic distance that may have relevance for specific countries. Brewer (2007: 88) also indicates that, "In addition to national characteristics or conditions that are most likely to be important to psychic distance, the particular characteristics of the managers of a firm might also be important. This is because it is the managers not nations that perceive psychic distance".

Thus Brewer (2007) recognizes that formative indicators such as the psychic distance index he constructed are highly context dependent, and when applied to different countries, industries and entry methods would require major adjustments. He also recognizes the importance of incorporating management's subjectivity in deliberations over the decision-making process.

The psychic distance paradox

At the most basic level, a aparadox is "a statement or proposition which, despite sound (or apparently sound) reasoning from acceptable premises, leads to a conclusion that seems logically unacceptable or self-contradictory" (Oxford Dictionary, 2017). The psychic distance paradox is thus seen to be evident where psychically close countries do not generate superior company performance. In this way, the so-called 'psychic distance paradox' has arisen from studies that purport to show that business interests are not always served by investments made in countries considered to be psychically close, in the way psychic distance explanatory model proposes. For example, O'Grady and Lane (1996) in an early study of this phenomenon, maintain that perceived similarities between countries can make managers overlook and remain unprepared for possible differences and by doing so, fail in making rational decisions. Expectations about psychic closeness may lead to unforeseen entry barriers and result in unsuccessful company performance.

Fenwick, Edwards and Buckley (2003) indicate that culturally close markets may result in reduced risk in entering and operating in a foreign market, there is no guarantee that it will result in successful company performance. Since cultural differences are seen as a core aspect of psychic distance per se, this finding is regarded as supportive of the paradox. Fenwick's et al. (2003) research suggests that company 
performance in psychically close markets can be negatively affected by unanticipated cultural differences. Perceived similarities between countries resulted in overconfidence and poor management preparation.

Evans, Treadgold and Mavondo (2000) point out that psychic distance may positive impacts on organizational performance. The uncertainty and risks linked to psychically distant markets makes companies invest additional time and more money on planning and research activities which results in better organizational performance.

Dikova (2009) suggests in contradiction to the psychic distance paradox model indicated in the above studies that market uncertainties in psychically distant markets motivates company management to research such markets more thoroughly, which can result in the better performance of foreign subsidiaries. The above studies indicate that the rationale for the apparent paradox resides in explanations stemming from shifts in independent variables rather than the same independent variable (psychic distance) becoming a paradox which is logically self-contradictory. The new independent variables explaining the 'paradox' are thus distinct from the original one of psychic distance, and in the above studies are found to be: management unpreparedness (O'Grady and Lane,1996), management overconfidence (Fenwick et al, 2003) and management research and planning (Evans et al, 2000; Dikova, 2009).

More recently, Gairola and Chong (2012) have incorporated psychic distance in computer simulations of cooperation to generate more realistic noise models in empirically-validated spatial games. Gairola and Chong (2012) investigate a novel 'psychic noise model' based on the idea of a psychic distance effect that they suggest, reflects real-world interactions. Gairola and Chong (2012) purport that psychic noise that influences interactions between individuals, depends on their psychic distance (e.g., cultural difference). Results from their extensive computer simulations which use a multi-agent system framework to assess the impact of various constructions of noisy interactions, show that noise has a negative impact on cooperation. However, Gairola and Chong (2012) also obtain results which they regard as "reminiscent of the psychic distance paradox" (op.cit:271), where increases in psychic 'noise levels' lead to decreases in inter-individual cooperation. Where 'noise' is defined as the faulty transmission of strategic choices and 'psychic noise' is regarded as arising from differential psychic distances between interacting people. This finding can be regarded as an equivocal manifestation of the psychic distance model's paradox in that it suggests that psychic distance and resultant pay-offs (where average pay-off values indicate the degree of cooperation) follow the form of a U-shaped curve, where increasing psychic distance appears to reduce average cooperation pay-offs and then, as psychic distance increases beyond a certain point, begin to improve cooperative pay-offs. Gairola and Chong (2012) regard this as evidence of a psychic distance paradox, but it is clear that it has fundamental qualitative differences from earlier empirical studies (e.g. those by O'Grady and Lane, 1996; Evans et al, 2000). In their analysis of the noise effects of spatial distances, Gairola and Chong (2012) found that neighbourhood size (with greater size being equivalent to greater distance) was associated, initially, with declining average pay-offs, but later with increasing average pay-offs with increasing neighbourhood size (see Figure 1).

Note that this finding, although logically consonant with the notion of the existence of a psychic distance paradox, is quite distinct from the paradox found in some empirical business studies. Here the paradox relates to greater psychic distance being associated with greater payoffs, whereas in most empirical business studiesof the phenomenon the paradox relates to smaller pay-offs being associated with closer psychic distance. It would seem, therefore, that working from the general premise that lower psychic distance promotes greater benefits, the paradox cannot logically be both that closer psychic distance promotes lesser benefits and further psychic distance promotes greater benefits at the same time, as it would suggest that the paradox is constituted of both negative and positive associations with psychic distance, when the concept itself is generally regarded as unidirectional. 
Figure 1. The psychic distance paradox (Gairola and Chong, 2012)

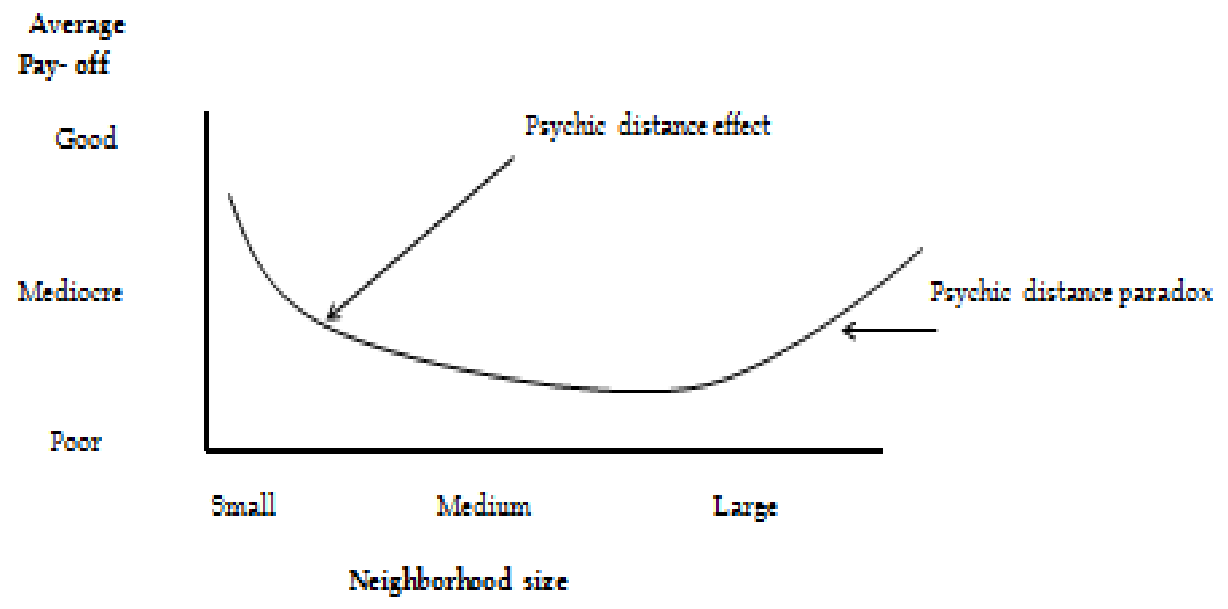

The paradox effect noted by Gairola and Chong (2012) and illustrated in Figure 1 cannot be explained by means of rationale of any of the empirical business studies mentioned earlier, here the effect seems to be one of, beyond a certain point, the greater the psychic distance the more effective cooperation and average pay-offs become. This finding might be explained by greater efficiencies derived from the relative lack of 'cultural ties' and need for personal involvement in more distant neighborhoods. As pointed out recently in a paper in the Economist (2017), cultural differences and lack of involvement can diminish the probability of cultural clashes which stem from "cultural incompatibilities".

\section{Methodology}

The preceding section has attempted to give an outline of the current situation regarding the definition and applications of the concepts of psychic distance and the psychic distance paradox published in the extant literature. The methodology used in the preceding section was one of logical inductive analyses of secondary data sources (Mill, 1843). The current section briefly discusses a methodological approach used in a recent empirical study of South African multinational company executives' decision-making which aims to resolve some of these conceptual and empirical problems which arise from the use of the psychic distance and paradox models discussed in the earlier section. The study (Joosub and Coldwell, 2016) adopted a cross-sectional research design using mixed methods combining nomothetic and idiographic approaches. A quantitative survey instrument was combined with qualitative semi-structured interviews and the findings of the analyses triangulated with a sequential research protocol. Table 2 below provides an overview of the mixed method sequential explanatory design discussed above.

\begin{tabular}{|l|l|l|}
\hline Phase & Procedure & Product \\
\hline Quantitative data collection & Cross sectional web based survey & Numeric data \\
\hline Quantitative data analysis & Analysis using SPSS & Descriptive statistics \\
\hline Qualitative data collection & In depth interviews & Interview transcripts \\
\hline Qualitative data analysis & Thematic and content analysis & Themes and commonalities \\
\hline $\begin{array}{l}\text { Integration of the qualitative and } \\
\text { quantitative results }\end{array}$ & Triangulation & Diversions \\
\hline
\end{tabular}

Table 2. The sequential explanatory design

Adapted from (Ivankova, Cresswell and Stick, 2006)

The research study consisted of three distinct phases implemented sequentially: quantitative, qualitative and triangulation. The quantitative phase consisted of closed-ended questionnaires emailed to the sample of respondents (data was analysed using SPSS descriptive statistics). The qualitative phase involved conducting a series of in-depth interviews with executive management (Atlas ti was used to 
interpret themes and commonalities that emerged from the data). Finally, the data were triangulated as a means of assessing the degree of corroboration between the nomothetic and idiographic data.

The quantitative population from which the non-random sample was obtained consisted of all South African Multinational enterprises (MNEs) that had operational foreign direct investments on 1 January 2012. The qualitative sample of 26 CEOs or directors involved in strategic decision making was non-randomly selected from a wide range of industries including: telecommunications, mining, engineering, retailing (food and clothing), paper manufacturers, service (legal and audit), banking, information technology, fast food and pharmaceuticals.

The quantitative and qualitative combined approach also has the potential benefit of surmounting limitations involved in using a single method. The qualitative and quantitative research instruments used similar conceptual ideas and focus which allowing the two paradigms to be connected and compared in an overall conceptual framework involving triangulation. The mix of the two methods provides a platform that allows the researcher to analyse 'seeing and hearing' data (Greene, 2008). It allows the researcher to understand the different and often difficult aspects of social phenomena by using multiple forms of inquiry (Greene, 2008:20).

Triangulation is regularly used to validate data obtained by the mixed method approach. As Webb, Campbell, Schwartz and Sechrest (1966:3) point out "Once a proposition has been confirmed by two or more independent measurement processes, the uncertainty of its interpretation is greatly reduced. The most persuasive evidence comes through a triangulation of measurement processes".

Triangulation is a method for corroborating and confirming qualitative and quantitative research findings by providing a third paradigm which consists of a synthesis which can provide more informative, complete and balanced. Triangulation is a validation strategy which provides more persuasive empirical evidence (Flick, 2009). Triangulation allows for convergence, validation and legitimation of results and a deeper understanding of the phenomenon being investigated and is able to create new knowledge through its synthesising process. (Denzin, 1989).

Methodological triangulation establishes validity between the different analytical methods used (Guion, 2002). In the South African study triangulation was used to describe the goodness of fit between the quantitative (survey instrument) and qualitative (interview) data. The findings of this triangulated synthetic analysis indicated corroboration of the nomothetic analysis by the idiographic analysis and validated the FDI factors found in the data analyses. Triangulation is thus a technique to generate a dialectic which goes beyond simply validating mixed method findings that are able achieve innovations of original conceptual frameworks which ".... is made possible through an ongoing dialectic of investigation. Essentially, this dialectic consists of a 'bottom-up' qualitative and 'top down' quantitative operationalisation of concepts in a dialectical synthesis that aims to validate existing research constructs and facilitate the emergence of further conceptual innovations" (Coldwell, 2007:7).

\section{Findings}

The findings of the inductive analysis of secondary sources (Mill, 1843) suggest that the concepts of psychic distance and the physic distance paradox are logically equivocal. In particular, the idea that psychic distance is theoretically sustainable as a unidirectional deficit model was shown to be untenable. Also, following from this, the equivocal nature of the psychic paradox was exposed by indicating that the paradox is sometimes regarded not only when low psychic distance is associated with unsuccessful FDI (its original meaning), but also when high psychic distance is associated with successful FDI.

Findings from the analyses using the innovative methodological approaches and techniques, suggest that geography (physical distance from head office) is a salient factor in FDI decision-making and agree with the original psychic distance model. However, the study found no unequivocal evidence that cultural differences, a major independent variable in the original model, affect the choice of FDI destination. Subjective elements of the management decision-maker not incorporated into objective, quantitative measurements of psychic distance incorporating objective indices, were often found to involve broader analyses of FDI opportunities. Management decision-makers perceptions of broader, dynamic contextual FDI factors and their own personal experience of the internationalization process, often weighed more heavily on the ultimate decisions made than objectively measurable psychic distance factors of the kind analysed in the original model. There was clear evidence that personal experiences of 
top management moderated FDI decision-making. More specifically, it was found that managers with personal experience of international locations (through work experience, business and social networks) were more likely to indulge in FDI.

Although based on a study limited to one country and with a small sample, the findings tentatively show that research relating to company internationalisation and FDI should include a qualitative dimension if it is to obtain dynamically valid results. Purely objective indices such as those used in psychic distance measurement are unlikely to embrace the dynamic subjective feature of FDI decision -making, not only in terms of what objective variable are contextually pertinent at a given moment in time, but also their relative importance.

The study also has indicated the crucial importance of contextual aspects in the explanation of FDI decision making; every firm sees FDI from its own unique perspective and responds from its bounded rationality and partial information possessed by decision-makers according to its interests and values rather than simply 'information deficits' as proposed in the psychic distance model. The qualitative dimension of the study and the triangulated methodology used in corroboration with the quantitative aspects, suggests that the unidimensional perspective of the psychic distance model is unable to capture the complexity of the FDI decision making process and that this is better understood by adopting a broader perspective with subjective and contextually dynamic inputs.

\section{Conclusion}

In general terms, psychic distance might be regarded as a view arising from a widely-held conviction that, as Nietzsche puts it, "invisible (psychic) threads are the strongest ties" (Colli, and Montinari, 1998). While a paradox is defined as "a statement or proposition which, despite sound (or apparently sound) reasoning from acceptable premises, leads to a conclusion that seems logically unacceptable or self-contradictory (Oxford Dictionary, 2017) this paper has indicated that such invisible psychic threads do not always provide strong ties and benefits they are purported to do in the psychic distance model. The analysis has shown that the concept of psychic distance and the psychic distance paradox become tenuous in both its empirical and theoretical usages. In short, the model of psychic distance is empirically flawed because it embraces partial and eclectic view of how the internationalization process occurs and theoretically flawed because empirical and computer simulated evidence suggests that psychic distance is both positively and negatively correlated with company internationalization success. In such circumstances also, the idea of a psychic distance paradox becomes logically inconsistent. The paper has also indicated that if psychic distance is 'disembodied' from the individual's psyche and merely measured by objective indices of its effects, it cannot be regarded as a truly psychic construct derived from individual subjective perceptions and experiences and has suggested that in order to do so, methodological adaptations in the way the concept is used in the South African study described in the paper are required.

Limitations of the study include the fact that the triangulated nomothetic and idiographic methodological approach to FDI decision-making used in the South African study has only been conducted with a relatively small sample of multinational companies in one specific context. Also, the equivocality of the psychic paradox has been shown by computer simulations and requires further substantive investigation. However, Brewer's (2007) acknowledgement of the fact that that the psychic distance concept is contextually bound, and that management's subjective decision-making process is crucial to explain the actual internationalization process, suggests that a broad and multi-faceted methodological approach is warranted. Future research using the triangulated quantitative and qualitative methodological approach with larger samples from different organizations in different industrial contexts and countries is therefore recommended.

Finally, there seems little doubt, as has been argued in this paper, that an idiographic dimension is needed in applications of a psychic distance concept if it is to validly reflect actual FDI decision-making processes and successfully combine the complex array of objective criteria and subjective world views that impinge on internationalisation decisions reached by managers in the real world. 


\section{References}

Amighini, A.A., Rabellotti, R. \& Sanfilippo, M. (2013). “Do Chinese state-owned and private enterprises differ in their internationalization strategies?" China Economic Review, 27(1), 312-325.

Arenius, P. (2005). The psychic distance postulate revised: From market selection to speed of market penetration. Journal of International Entrepreneurship, 3(2), 115-131.

Bai, C. \& Sarkis, J. (2010). Green supplier development: Analytical evaluation using rough set theory. Journal of Cleaner Production, 18(12), 1200-1210.

Beckerman, W. (1956). Distance and the pattern of intra-European trade. The Review of Economics and Statistics, 38(1), 31-40.

Benito, G. R., \& Gripsrud, G. (1992). The expansion of foreign direct investments: Discrete rational location choices or a cultural learning process? Journal of International Business Studies, 461-476.

Blomkvist, K. \& Drogendijk, R. (2013). The Impact of Psychic Distance on Chinese Outward Foreign Direct Investments. Management International Review, 53(5), 659-686.

Brewer, P. (2007). Operationalizing Psychic Distance: A Revised Approach. Journal of International Marketing, 15(1), 44-66.

Bullough, E. (1912). Psychic distance as a factor in art and an aesthetic principle. British Journal of Psychology, 5(2),87-118.

Campbell, J.T., Eden, L. \& Miller, S.R. (2012). Multinationals and corporate social responsibility in host countries: Does distance matter? Journal of International Business Studies, 43(1), 84-106.

Cavusgil, S.T. (1980). On the internationalization process of firms. European Research, 8(6), 273-281.

Chetty, S. \& Campbell-Hunt, C. (2004). 'A strategic approach to internationalization: A traditional versus a 'born-global' approach', Journal of International Marketing, 12, 57-81.

Child, J., S.H. Ng, and C. Wong. (2002). Psychic Distance and Inter nationalization: Evidence from Hong Kong Firms, International Studies of Management and Organization, 32 (1), 36-56.

Conway, T. \& Swift, J. (2000). 'International relationship marketing: The importance of psychic distance', European Journal of Marketing, 34, 1391-414.

Covin, J.G. \& Miller, D. (2014). International entrepreneurial orientation: Conceptual considerations, research themes, measurement issues, and future research directions. Entrepreneurship Theory and Practice, 38(1), 11-44.

Coldwell, D.A.L. (2007). Is Research that is both causally adequate and adequate on the level of meaning possible or necessary in business research? A Critical analysis of some methodological alternatives. Electronic Journal of Business Research Methods, 5(1), 1-10.

Colli, G. and Montinari, M. (1998). F. Nietzche Nachgelassene Fragmente 1882-1884 Berlin: De Gruyeter.

Dent, C.M. (2016). East Asian regionalism. London: Routledge

Denzin, N.K. (1989). The Research Act. 3rd edition. Englewood Cliffs, NJ: Prentice-Hall.

Dikova, D. (2009). Performance of foreign subsidiaries: Does psychic distance matter? International Business Review, 18 (1), 38-49.

Dow, D. \& Karunaratna, A. (2006). Developing a multidimensional instrument to measure psychic distance stimuli. Journal of International Business Studies, 37(5), 578-602

Economist. (2017). 'Say my name'. 18 March p. 31

Evans, J; Treadgold, A. \& Mavondo, F.T.(2000). Psychic distance and the performance of international retailers - A suggested theoretical framework. International Marketing Review, 17 (4/5), 373 - 391.

Ekroos, E. \& Sjöberg, C. (2012). 'The effect of management's perception of psychic distance on organizational performance in a foreign market - A case study of Bufab Sweden and Bufab Finland'. Master's dissertation: International Marketing. Högskolan, Sweden: Halmstad University.

Fenwick, M., Edwards, R. \& Buckley, P. J. (2003). Is cultural similarity misleading? The experience of Australian manufactures in Britain. International Business review, 12 (3), 297-309.

Flick, U. (2009). An introduction to qualitative research. Thousand Oaks, CA: Sage Publications.

Gairola, D. and Chong S.Y. (2012). 'An economics-inspired noise model in spatial games with reputation'. In Kolodziej, J. Eds Advances in intelligent modelling and simulation, 271-293. Berlin: Springer-Verlag.

Greene, J.C. (2008). Is mixed methods social inquiry a distinctive methodology? Journal of Mixed Methods Research, 2(1), 7-22. 
Guion, R.M. (2002). Validity and reliability. In Rogelberg, S.G. (eds.), Handbook of research methods in industrial and organizational psychology, 57-76. Malden, MA: Blackwell.

Holm, U., Forsgren, M. \& Johanson, J. (2015). Knowledge, Networks and Power: The Uppsala School of International Business. Förlag: Palgrave Macmillan.

Ivankova, N.V., Creswell, J.W. \& Stick, S.L. (2006). Using mixed-methods sequential explanatory design: From theory to practice. Field methods, 18(1), 3-20.

Johanson, J., Vahlne, J-E. (1977). The internationalisation process of the firm: a model of knowledge development and increasing foreign market commitments. Journal of International Business Studies, Spring/Summer 8, 23-32.

Johanson, J., Wiedersheim-Paul, F. (1975). "The internationalization of the firm - four Swedish cases", Journal of Management Studies, 12 (3), 305-22.

Joosub, T. \& Coldwell, D.A.L. (2016). Factors driving the location investment decision of South African MNEs: Senior executives' perceptions' Southern African Business Review. 20.

Kiss, A.N., Danis, W.M. \& Cavusgil, S.T. (2012). International entrepreneurship research in emerging economies: A critical review and research agenda. Journal of Business Venturing, 27(2), 266-290.

Kotabe, M., Jiang, C.X. \& Murray, J.Y. (2011). Managerial ties, knowledge acquisition, realized absorptive capacity and new product market performance of emerging multinational companies: A case of China. Journal of World Business, 46(2), 166-176.

Lee, D.J. (1998). The effect of cultural distance on the relational exchange between exporters and importers: The case of Australian exporters, Journal of Global Marketing, 11, 7-22.

Li, J. \& Guisinger, S. (1992). The globalization of service multinationals in the "triad" regions: Japan, Western Europe and North America. Journal of International Business Studies, 23(4), 675-696.

Linnemann, H. (1966). An econometric study of international trade flows. Amsterdam: North-Holland.

Lockwood, B. (2004). How robust is the Kearney/foreign policy globalisation index? The World Economy,

27(4), 507-523.

Mill, J.S. (1843). A system of logic, ratiocinative and inductive, being a connected view of the principles of evidence and the methods of scientific investigation. London: John W. Parker

Nordstrom, K.A. \& Vahine, J.E. (1994). Is the globe shrinking? Psychic distance and the establishment of Swedish sales subsidiaries during the last 100 years. In Landeck, M. (ed.), International Trade: Regional and Global Issues, 41-56. New York, NY: Palgrave Macmillan.

O'Grady, S., \& Lane, H. W. (1996). The psychic distance paradox. Journal of international business studies, 309-333.

Oxford Dictionary. (2017). 'Paradox'. Available at https://en.oxforddictionaries.com/definition/paradox

Rugman, A.M., Verbeke, A. and Nguyen, T. K. (2011). Fifty years of international business theory and beyond, Management International Review, 51,755-786.

Sim, A.B. \& Pandian, J.R. (2003). An exploratory study of internationalization strategies of Malaysian and Taiwanese firms. International Journal of Emerging Markets, 2(3), 252-273.

Stöttinger, B.\& Schlegelmilch, B.B. (2000). Explaining export development through psychic distance: Enlightening or elusive? International Marketing Review, 15(5),357-372.

Webb, E., Cambell, D., Schwartz, R. \& Sechrest, L. (1966). Unobtrusive measures: Nonreactive research in the social sciences. Chicago: Rand McNally.

Vahlne, J.E. \& Wiedersheim-Paul, F. (1973). Psychic Distance: An inhibiting factor in

international Trade, Centre for international Business Studies: University of Uppsala.

Zaheer, S. (1995). Overcoming the liability of foreignness. Academy of Management Journal, 38(2), 341-363. 